\title{
Dispositional Optimism and Coping With PAin
}

\author{
K. Bargiel-Matusiewicz, A. Krzyszkowska \\ Faculty of Psychology, Warsaw University, Warsaw, Poland
}

\begin{abstract}
Objective: The aim of this article is to analyze the relation between dispositional optimism and coping with chronic pain. The study seeks to define the relation between life orientation (optimism vs. pessimism) and coping with pain (believes about pain control and the choice of coping strategy).

Material and methods: The following questionnaires were used: LOT-R - Life Orientation Test, BPCQ - The Beliefs about Pain Control Questionnaire and CSQ The Pain Coping Strategies Questionnaire.

Results: The results show that dispositional optimism correlates positively with: internal locus of pain control $\mathrm{r}=0.6, \mathrm{P}<0.01$; declared coping with pain $\mathrm{r}=0.38$, $\mathrm{P}<0.05$; diverting attention $\mathrm{r}=0.93, \mathrm{P}<0.01$; and behavioral activity $\mathrm{r}=0.82, \mathrm{P}<0.01$. Dispositional optimism correlates negatively with catastrophizing $\mathrm{r}=$ $-0.28, \mathrm{P}<0.05$.

Conclusions: We conclude that dispositional optimism plays a key role in forming the mechanisms of coping with chronic pain and thereby in improving the psychophysical comfort of patients.
\end{abstract}

Key words: dispositional optimism, pain

\section{INTRODUCTION}

In recent years, rapid developments of research on mutual interaction between physiological processes and psychological functions of an individual and on psychological factors connected with pain suffering have been observed [1-5]. Pain has two fundamental aspects. The first is sensory, connected with the perception of pain. Thanks to it, it is possible to locate the pain. The second is emotional, being connected with the character of a psychological reaction to the pain stimulus. The emotional component of pain is, to a large extent, subjective; therefore, the feeling of pain differs in individual persons $[3,6,7]$. According to bio-psycho-social model, along with the transformation of acute pain into chronic pain, an increasingly greater role in sustaining pain sensations and behaviors is played by psycho-social factors. Thus, pain is actually a personal, internalized, and multi-level experience.

Subjective factors which decide about the way information connected with pain is perceived are, in the first instance, previously encoded and shaped cognitive schemes related to health, illness, and the way of coping with a situation. Health and psychological condition depend to a certain degree on both: the nature of stressful incidents (e.g., pain, illness) and the very efforts undertaken to handle a given situation $[4,8]$. A key element modulating pain sensation is its reception and cognitive assessment. When analyzing the course of psychological processes of coping with pain, attention should be drawn to the factors which may support an individual in their efforts to reduce sensations or get control over stressful experiences. One of such factor is an individual's conviction about having control over what happens in life or about the ability to influence and change the course of events $[4,6,7,9]$.

Apart from the sense of control, an important role in the analysis of psychological mechanisms of coping is attributed to the sense of self-efficacy, which is strongly related to the previous resource. It is believed that self-efficacy influences decisions to undertake a given activity, the amount of effort put in it, or persistence in action. This kind of internal assessment of future individual's action does not constitute a permanent disposition, but rather refers to a specific situation context. However, if individual's self-efficacy is too little, he usually acts ineffectively, even though he knows how he should act. People who experience doubts about their capabilities, reduce efforts, or totally give up when facing a problem [9].

Contemporary psychology ascribes a significant meaning in the psychological regulation of individual's behaviors to his expectations. It is believed that if a person expects that his actions will bring desired results, he will undertake efforts to achieve them, even though the progress is slow and hard to make. Generalized expectations toward the future make up an important aspect of personality, defined by Scheier and Carver [10] as the dispositional optimism. It is a conviction that rather positive than negative happenings will occur in life. Research carried out by Scheier and Carver [11] shows that optimistic expectations toward the results of one's own activities, and also toward the future, allow people to have better subjective frame of mind when facing various stressful events and to apply more active strategies of coping. Thus, optimism seems to be a good predictor of constructive coping with stress, including illness and pain [12]. The reasons for a positive influence of dispositional optimism on psychophysical well-being are suspected in undertaking dissimilar defensive strategies. As it was mentioned, optimists tend to rely on active coping, while 
pessimists frequently apply escape-like solutions. What is more, optimists are more ready to accept the realities of stressful situations, they act more persistently and consistently [9]. Similar conclusions, i.e., optimism being a resource moderating coping in a stressful situation, have been drawn by Seligman [13]. According to his theory, it is not only the ability to control aversive stimuli, but, in the first instance, the way of interpreting these stimuli by a person that decides about a certain habitual way of coping. Generalized negative interpretation (pessimism) leads to passiveness and depression, so called learned helplessness, which is clearly a non-adapting strategy.

The aim of the present study is to define a relation between the kind of life orientation (optimism vs. pessimism), and coping with pain (believes about pain control and the choice of coping strategy). In the study, life orientation approach according to Scheier and Carver's theory [10] was used. Based on this theory LOT-R - Life Orientation Test was constructed [12]. Dispositional optimism is defined herein as a factor favorable for physical well-being and the ability to resist stress-inducing life experiences, which, in turn, is crucial for health and for undertaking pro-health behaviors.

\section{Material AND Methods}

The study was approved by an institutional Ethics Committee. The following questionnaires were used:

1/ The Life Orientation Test (LOT-R), developed by Scheier, Carver, and Bridges [14], in a Polish adaptation by R. Poprawa and Z. Juczynski. The test analyzes generalized expectations of an individual toward the future. These expectations constitute one personality aspect, called dispositional optimism. LOT-R reliability was calculated on the basis of Cronbach's alfa co-efficient value as 0.76 [12].

2/ The Beliefs about Pain Control Questionnaire (BPCQ), developed by Skevington [15]. A Polish adaptation of the questionnaire was done by Z. Juczynski. BPCQ contains 13 statements, composing three elements that measure the strength of individual believes related to pain control. Three sources of pain control, examined in the frames of BPCQ are: personal control (internal locus of control); doctors' influence, and the influence of random events. Cronbach's alfa co-efficient, for the whole questionnaire, is 0.75 [12]. In the present study, a relation between dispositional optimism and internal locus of pain control was analyzed.

3/ The Pain Coping Strategies Questionnaire (CSQ), developed by Rosenstiel and Keefe [16] in a
Polish adaptation by Z. Juczynski. The questionnaire is used to evaluate applied strategies to cope with the pain experienced and to evaluate these strategies' efficiency in controlling pain. It comprises 42 statements describing various methods of coping with pain and two questions for the evaluation of one's own skills to control pain. The ways to cope with pain reflect six cognitive strategies (reassessment of pain sensation, sensations ignoring, one's declaration of coping with pain, diverting attention, catastrophizing, praying/pining) and one behavioral strategy (increased behavioral activity). Cronbach's alfa co-efficient, for the whole questionnaire, is 0.80 [12]. Here we analyzed relations between dispositional optimism and selected strategies of coping with pain, such as: diverting attention, increased behavioral activity, catastrophizing, and individual's declaration of coping with pain.

The study was conducted in 65 persons; three sets of questionnaires were rejected due to some missing data. Eventually, the results obtained from 62 persons were analyzed; including 34 women $(54.8 \%)$ and 28 men $(45.2 \%)$ aged 24 to 65 . The examined were patients suffering from rheumatoid arthritis, back-ache, or neuropathy. The survey was conducted in rehabilitation centers in the cities of Warsaw and Radomsko.

Normality of data distribution was checked with the Kolmogorow-Smirnow test. For further statistical procedures, parametric Pearson's r test was applied.

\section{RESULTS AND DisCUSSION}

The Kolmogorow-Smirnow test rejected the null hypothesis that the variables studied were not normally distributed. The results of the analysis are presented in Table 1.

Table 1. Results of Kolmogorow-Smirnow test.

\begin{tabular}{lll}
\hline Variables & Z statistics & Significance \\
\hline Dispositional optimism & 0.682 & $\mathrm{P}=0.418$ \\
Internal locus of control & 0.739 & $\mathrm{P}=0.646$ \\
Declaration of coping with pain & 0.806 & $\mathrm{P}=0.535$ \\
Diverting attention & 1.281 & $\mathrm{P}=0.075$ \\
Behavioral activity & 1.025 & $\mathrm{P}=0.234$ \\
Catastrophizing & 0.946 & $\mathrm{P}=0.332$ \\
\hline
\end{tabular}

Table 2 demonstrates the analysis of correlation of dispositional optimism with the variables describing the ability of coping with pain. An optimistic life ori-

Table 2. Correlation between dispositional optimism and coping with pain.

\begin{tabular}{llll}
\hline & & Pearson's $r$ coefficient & Significance \\
\hline Dispositional optimism & Internal locus of control & 0.60 & $\mathrm{P}<0.01$ \\
& Declaration of coping with pain & 0.38 & $\mathrm{P}<0.05$ \\
& Diverting attention & 0.93 & $\mathrm{P}<0.01$ \\
& Behavioral activity & 0.82 & $\mathrm{P}<0.01$ \\
& Catastrophizing & -0.28 & $\mathrm{P}<0.05$ \\
\end{tabular}


entation related highly positively with the variables of pain control and negatively with the catastrophic attitude.

The higher was the level of dispositional optimism, the stronger internal pain control $(\mathrm{r}=0.60, \mathrm{P}<0.01)$. It means that dispositional optimism is favorable for more active ways of coping with pain, since the optimism is a consequence of internal feeling of being in control. A positive role of this feeling may be observed, for instance, from the results obtained in a study performed in cardiac patients. Patients, who face heart failure, when have a feeling of internal control over their situation achieve better treatment progress [17]. Relations between dispositional optimism, on the one side, and the selection of strategy for coping with pain and the subjective assessment of coping, on the other side, found in the present study show that individuals with positive attitude more frequently use cognitive strategy connected with attention diversion $(\mathrm{r}=0.93, \mathrm{P}<0.01)$ and have a higher tendency to undertake behavioral activities, which enables to distance them from pain sensation, and thus decreases pain intensity $(\mathrm{r}=0.82 \mathrm{P}<0.01)$. It may be stated that dispositional optimism prevents excessive focusing on pain sensations, which usually accompanies pain assessment as a dangerous stimulant. Other studies conducted so far on the subject shows that fear for pain may cause additional attention focusing on pain and pain related stimuli; strengthening the tendency not to undertake any activities. Consequences of avoiding activity rank high among other factors that gradually weaken patients' condition $[3,5,6,18]$.

In the present study we found a negative correlation between dispositional optimism and catastrophizing $(\mathrm{r}=-0.28, \mathrm{P}<0.05)$. It means that dispositional optimism, to some extent, prevents the feeling of all-embracing pain influence on patients' life and related perception of helplessness. Catastrophizing is generally treated as a product of worse pain coping skills. Previous research shows that patients with chronic pain are especially vulnerable to excessive generalization, personalization, selective perception, and catastrophizing. Catastrophizing seems to have especially big influence on pain and malfunction. A higher tendency for catastrophizing and undertaking less adaptive behavior strategies is linked with lower pain tolerance as well as with pain intensification and distress $[1,5,7]$. A natural consequence of the above discussed dependences is a positive correlation of dispositional optimism with the feeling of one's coping with pain $(\mathrm{r}=0.38, \mathrm{P}$ $<0.05)$. It means that dispositional optimism is favorable for a positive evaluation of one's own efforts connected with coping with pain, which may, in turn, strengthen the feeling of self-efficacy.

Summing up, the present results are consistent with those from other studies. In the literature, an opinion prevails that dispositional optimism has a positive influence on psychological well-being, by releasing more active strategies of coping, undertaking more efforts, and a constructive approach when facing failures. Similar results have been achieved when analyzing patients suffering from coronary heart disease. Persons with an optimistic attitude toward life have much better physiological results of coping with pain than pessimists do
[9]. Research with application of the most advanced technologies for brain imaging show how cognitive processes, emotions, and learning may modify the processing of information sent to brain sensory areas. Functional magnetic resonance shows that different parts of the brain are engaged in feeling pain and its anticipation. More importantly, activity level in the areas connected with cognitive and emotional competences of pain is susceptible to changes in the areas processing sensory pain information [19]. Thus, a conclusion may be stated that dispositional optimism plays a key role in forming the mechanisms of coping with chronic pain and thereby in improving the psychophysical comfort of patients.

Conflicts of interest: No conflicts of interests were declared by the authors in relation to this article.

\section{REFERENCES}

[1] Eccleston Ch, Crombez G (2007) Worry and chronic pain: A misdirected problem solving model. Pain 132: 233236.

[2] Robles TF, Glaser R, Kiecolt-Glaser JK (2005) Out of Balance. A new Look at chronic stress, depression, and immunity. Psychol Sci 14: 111-115.

[3] Thorn BE. Cognitive Therapy for Chronic Pain: a step-bystep guide. New York, Guilford Press, 2004.

[4] Ortenburger D. Czynniki psychologiczne w bólu przewleklym (in Polish). Published by the Jan Dlugosz Academy, Czestochowa, Poland, 2008.

[5] Van Damme S, Crombez G, Van Nieuwenborgh-De Wever K, Goubert L (2008) Is distraction less effective when pain is threatening? An experimental investigation with cold pressor task. Eur J Pain 12: 60-67.

[6] Bantick SJ, Wise RG, Ploghaus A, Clare S, Smith SM, Trace I (2002) Imaging how attention modulates pain in humans using functional MRI. Brain 125: 310-319.

[7] Turk DC, Monarch ES. Biopsychosocial perspective on chronic pain. In Psychological Approaches to Pain Management. DC Turk, RJ Gatchel (eds). Guilford Press, New York, 2002, pp. 3-29.

[8] Heszen I, Sek H. Health Psychology (in Polish). Warszawa, PWN, 2007.

[9] Poprawa R. Zasoby osobiste w radzeniu sobie ze stresem (in Polish). In: Elements of Health Psychology. G Dolinska-Zygmunt (ed), Wroclaw University Publishing House, 1996, pp. 101-136.

[10] Scheier MF, Carver CS (1992) Effects of optimism on psychological and physical well-being: Theoretical overview and empirical update. Cognit Ther Res 16: 201-228.

[11] Scheier MF, Carver CS (1985) Optimism, coping, and health: Assessment and implications of generalized outcome expectations. Health Psychol 4: 219-247.

[12] Juczynski Z. Narzedzia pomiaru w promocji i psychologii zdrowia (in Polish). Laboratory of Psychological Tests of the Polish Psychological Society, Warsaw, Poland, 2001.

[13] Seligman ME. Optymizmu mozna sie nauczyc (in Polish). Publishing House Media Rodzina, Poznan, 1993.

[14] Scheier MF, Carver CS, Bridges M (1994) Distinguishing optimism from neuroticism (and trait anxiety, self-mastery, and self-esteem): A reevaluation of the Life Orientation Test. J Pers Soc Psychol 67: 1063-1078.

[15] Skevington SM (1990) A standardised scale to measure beliefs about controlling pain (BPCQ): a preliminary study. Psychol Health 4: 221-232. 
[16] Rosenstiel A, Keefe FJ (1983) The use of coping strategies in chronic low back pain patients: relationship to patient characteristics and current adjustment. Pain 17: 3344.

[17] Vagi AB, Lefcourt HM (1988) Investigativeness as a moderator of stress. J Behav Sci 20: 93-108.

[18] Crombez G, Vervaet L, Lysens R, Baeyens F, Elen P (1998) Avoidance and confirmation of painful, backstraining movements in chronic back pain patients. Behav Modif 22: 62-77.

[19] Ploghaus A, Trace I, Gati JS, et al (1999) Dissociating pain from its anticipation in the human brain. Science 5422: 1979-1981.
Corresponding author:

Kamilla Bargiel-Matusiewicz

Faculty of Psychology

Warsaw University

5/7 Stawki St.

00-183 Warsaw, Poland

Phone: +48 225549703

k.matusiewicz@op.pl 